\title{
New Possibility for REE Determination in Oil
}

\author{
Alexander Soin, ${ }^{1}$ Tatiana Maryutina,,${ }^{1,2}$ Natalya Musina, ${ }^{1}$ and Andrey Soin ${ }^{1,2}$ \\ ${ }^{1}$ United Research and Development Centre, Leninsky prospect 55/1 Building 2, Moscow 119333, Russia \\ ${ }^{2}$ Vernadsky Institute of Geochemistry and Analytical Chemistry, Russian Academy of Sciences, Kosygin Street 19, \\ Moscow 119991, Russia \\ Correspondence should be addressed to Tatiana Maryutina, tatiana@maryutina.com \\ Received 17 December 2011; Accepted 24 January 2012 \\ Academic Editor: S. Michael Angel \\ Copyright () 2012 Alexander Soin et al. This is an open access article distributed under the Creative Commons Attribution License, \\ which permits unrestricted use, distribution, and reproduction in any medium, provided the original work is properly cited.
}

A novel approach of rare earth elements (REE) determination in crude oil is suggested. Special application of countercurrent chromatography (CCC) is used as a sample pretreatment tool. An oil sample is continuously pumped through the rotating coil column (RCC) as a mobile phase, while an aqueous phase (nitric acid solution) is retained as a stationary phase. Two phases are kept well mixed and agitated, but there is no emulsion at the interface under the chosen conditions. Special features of CCC give an opportunity to vary the volume of oil samples to be analyzed from $10 \mathrm{~mL}$ to $1 \mathrm{~L}$ or more. Trace metals are preconcentrated into $10 \mathrm{~mL}$ of stationary phase (acidic solutions) pumped out of the column so that analysis can be easily determined with inductively coupled plasma mass spectrometry (ICP-MS) without additional sample preparation procedures. Optimal concentration of nitric acid in the stationary phase for preconcentration of REE from oil by CCC has been investigated. The combination of CCC with ICP-MS gives the possibility to develop a rapid, reliable, and accurate method of trace metal including rare earth elements (REE) determination in crude oils and oil products. Such method could be an alternative for unexpanded and expensive neutronactivation analysis (NAA).

\section{Introduction}

Microelemental and REE contents of oil are very important for estimating oil's age and for developing theories of oil's origin. It is known that information about hydrocarbons genesis could be obtained using element ratios. Such ratios also could be determinative as the georeconnaissance data. From this point of view, REE content/ratios are of the prime interest. REE ratios could be used as the reference points for different oils (from different deposits/fields) like for most geological samples as rocks, minerals, and ores $[1,2]$.

In the meantime, REE analysis of oils is still a very complicated analytical task. There are no methods of preconcentration of metals from oil to aqueous phases, and REE contents are usually at ppt level and lower. Also there are no standard methods (ASTM D, IP, EN, or UOP) or standa$\mathrm{rd} /$ reference samples for REE analysis of oils. It should be mentioned that articles and studies dedicated to REE content in oils could be found really seldom. Thus, ICP-MS determination of REE in oils was published [3] when acid digestion was used for sample preparation. As a result, most of REE, measured (including Pr, Sm, Eu, Gd, Dy, Er and $\mathrm{Yb}$ ) were "not detected."

Suggesting hybrid method (CCC and ICP-MS) enables lessening detection limit (DL) and detecting most of metals in oil including REE.

Abilities of the liquid stationary phase retention during pumping of oil samples through column enable isolation and preconcentration of the inorganic impurities into acidic aqueous solutions. In this case, CCC can be used as a tool for the sample pretreatment and preparation. Preliminary investigations on retention features of oil/oil products-aqueous phase systems in CCC, were published $[4,5]$.

The main characteristic of sample preparation methods is recovery values. It is preferable to compare recoveries of inorganic impurities from oil by extraction method and other instrumentation techniques. If that instrumentation method enables direct oil analysis, then comparison will be more reliable. Thus, NAA was used in this work. Aforesaid issue of standard/reference samples is a real problem for extraction/leaching methods as well. Therefore, relative contents of REE were mainly used. 
Thus, regardless of the geological and tectonic structure of the source regions, oil composition, depth of deposit occurrence, and lithology of the enclosing rocks, the distribution curves of REE are usually highly differentiated. It has been shown also that total quantity of lanthanides $\left(\Sigma \operatorname{Ln}_{\mathrm{N}}\right)$ has a very wide range from 0.5 to $5.8 \mathrm{mg} / \mathrm{t}(3.0 \mathrm{mg} / \mathrm{t}$ on average) in West Siberian and Kazakhstani oils. As an example, fluids of cooling magma pockets of increased alkalinity are the major source of lanthanides in oil. They are involved in oil enrichment with light lanthanides and formation of the positive Eu anomaly [6].

Main objective of this work was to estimate CCC-ICP-MS approach to REE determination of oils from different sources and to compare with the results obtained by NAA.

\section{Experimental}

2.1. Reagents and Materials. High-purity deionized water (resistivity $18.2 \mathrm{~m} \Omega$ ) obtained from a Milli-Q water purification system (Millipore, Canada) and ultrapure nitric acid $\mathrm{HNO}_{3}$ (Merck, Germany) for aqueous solution preparing and decomposition of oil samples and as a stationary phase has been used.

In the quantitative elemental analysis by ICP-MC, we prepared standard solutions by diluting multielement agilent standard A (Al, As, Ba, Be, Bi, B, Cd, Ca, Ce, Cs, Cr, Co, Cu, Dy, Er, Eu, Gd, Ga, Ho, In, K, Fe, La, Li, Lu, Mg, Mn, Na, Nd, Ni, P, Pb, Pr, Rb, Re, Sm, Sc, Se, Sr, Tb, Th, Tl, Tm, U, $\mathrm{Yb}, \mathrm{Y}, \mathrm{V}$, and $\mathrm{Zn} 10 \mu \mathrm{g} / \mathrm{mL} \pm 0.5 \%$ in $\left.2 \% \mathrm{HNO}_{3}\right)$. Elements concentration range for all the elements was $1-100 \mu \mathrm{g} / \mathrm{L}$.

Calibration coefficients of determination for all elements were $0.9995-0.9999$. Recovery tests were performed using "Trace metals in drinking water" solution (with $2-250 \mu \mathrm{g} / \mathrm{L}$ concentrations of $\mathrm{Al}, \mathrm{As}, \mathrm{Ba}, \mathrm{Be}, \mathrm{Bi}, \mathrm{Cd}, \mathrm{Cr}, \mathrm{Co}, \mathrm{Cu}, \mathrm{Fe}, \mathrm{Pb}$, $\mathrm{Li}, \mathrm{Mn}, \mathrm{Mo}, \mathrm{Ni}, \mathrm{Rb}, \mathrm{Sb}, \mathrm{Se}, \mathrm{Sr}, \mathrm{Te}, \mathrm{Tl}, \mathrm{U}, \mathrm{V}, \mathrm{Zn}$, and $\mathrm{Ag}$ ), and recoveries were in the range of $91-112 \%$.

Experiments on trace and rare earth elements preconcentration were performed with light Kazakhstan (Tengizskaya) oil with density $\rho=0.795 \mathrm{~g} / \mathrm{mL}$ and viscosity $\eta=$ $2.270 \mathrm{~mm}^{2} / \mathrm{s}$, West Siberian oil (region) with $\rho=0.870 \mathrm{~g} / \mathrm{mL}$ and $\eta=17.90 \mathrm{~mm}^{2} / \mathrm{s}$ and composite oil with $\rho=0.828 \mathrm{~g} / \mathrm{mL}$ and $\eta=4.745 \mathrm{~mm}^{2} / \mathrm{s}$. Tengizskaya oil is a medium-sulfur oil ( $\mathrm{S}$ content $\sim 0.9$ mass.\%), West Siberian oil is a middle-sulfur oil ( $\mathrm{S}$ content $\sim 1.6$ mass.\%), and composite oil is a mediumsulfur oil ( $\mathrm{S}$ content $\sim 0.8$ mass.\%).

\subsection{Instruments}

2.2.1. RCC. Figure 1 schematically illustrates type $\mathrm{J}$ singlelayer synchronous planetary centrifuge. Typical column is formed by winding Teflon tubing around a cylindrical holder. Column holder rotates around its own axis and revolves around the centrifuge axis at the same speed $(\omega)$ and in the same direction. An aqueous solution is retained in column due to the complex gravitational (centrifugal) field, while the mobile phase (oil) is pumped through the column.

RCC experiments were performed with "Spring-3 M" J-type single-layer synchronous horizontal planetary centrifuge (made in the Institute for Analytical Instrumentation,

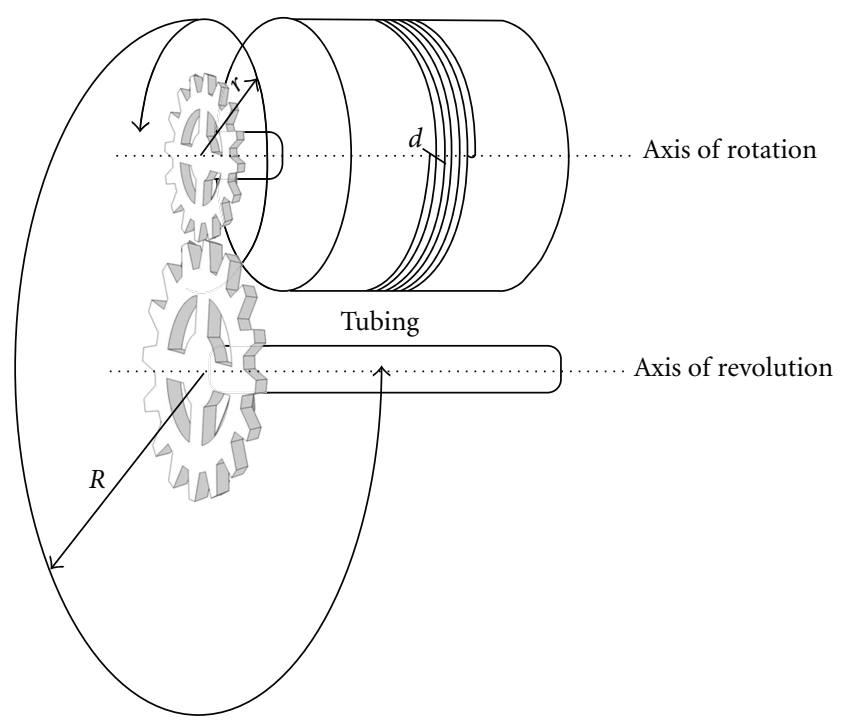

FIGURE 1: Scheme of planetary centrifuge.

St. Petersburg, Russia) with the total column volume of $19 \mathrm{~mL}$ at constant $T=20^{\circ} \mathrm{C}$. Scheme of planetary centrifuge is in Figure 1. RCC coiling diameter was $120 \mathrm{~mm}$, revolution radius was $93 \mathrm{~mm}$, and length of the tube was $1.15 \mathrm{~m}$. Phases were pumped through an RCC using a peristaltic pump (Masterflex, UK).

The column was filled with aqueous $\mathrm{HNO}_{3}$ solution while stationary. Then the planetary centrifuge is set to rotate at constant speed, and the mobile phase (oil or diesel) was pumped through the column from the top of the column to the bottom or "Head to Tail" $[4,5,7]$. Some volume of the aqueous acid solution is retained in the column as the stationary phase. All working parameters for the planetary centrifuge are shown in Table 1. After the experimental run, the acid solution was pumped out of the nonrotating column and analyzed by ICP-MS.

Toluene, iso-octane, and acetone of chemically pure grade were used for column rinsing. After every CCC experiment, $70-100$ of each solvent were pumped through the stationary column.

2.2.2. Autoclave Decomposition. To compare results of CCC elements isolation from oil with other techniques, autoclave decomposition of oil samples was used. Module "MKP-04" with autoclave NPVF "ANKON-AT-2" (Russia) was used for decomposition in a closed system. Standard conditions of autoclave decomposition are provided in Table 2. Oil samples were digested by concentrated ultrapure $\mathrm{HNO}_{3}$ in sealed Teflon containers and than cooled and diluted to $50 \mathrm{~mL}$ by deionized water (washing of containers sides). Total heating time of oil sample at different temperature conditions takes $4 \mathrm{~h}$. These diluted samples were analyzed by ICP-MS.

2.2.3. ICP-MS Determination. ICP-MS measures most of the elements with very low (ppb or even ppt) DLs. Minimization of large interferences was provided with a simple matrix of analyzed samples (diluted $\mathrm{HNO}_{3}$ solutions), maximal comp- 
TABLE 1: Working parameters of planetary centrifuge.

\begin{tabular}{|c|c|c|c|c|c|c|}
\hline $\begin{array}{l}\text { Mobile-phase } \\
\text { volume }\end{array}$ & $\begin{array}{l}\text { Stationary-phase } \\
\text { volume }\end{array}$ & $\begin{array}{c}\text { Centrifuge } \\
\text { rotation speed }\end{array}$ & $\begin{array}{c}\text { Beta ratio } \\
\text { (spool radius/rotor radius) }\end{array}$ & $\begin{array}{l}\text { Flow rate of } \\
\text { mobile phase }\end{array}$ & $\begin{array}{l}\text { Column } \\
\text { tubing bore }\end{array}$ & Temperature \\
\hline$V_{M}, \mathrm{~mL}$ & $V_{S}, \mathrm{~mL}$ & $\omega, \mathrm{rpm}$ & $\beta=r / R$ & $F, \mathrm{~mL} / \mathrm{min}$ & $d, \mathrm{~mm}$ & $T,{ }^{\circ} \mathrm{C}$ \\
\hline $19-110$ & 10 & 750 & 0.65 & $0.5 ; 1.2$ & 0.8 & 20 \\
\hline
\end{tabular}

TABLE 2: Conditions and working parameters of autoclaves decomposition of oil sample.

\begin{tabular}{lcccc}
\hline Sample mass & Acid volume & \multicolumn{3}{c}{ Time and temperature } \\
$m_{s}, \mathrm{~g}$ & $V_{\mathrm{HNO}_{3}}, \mathrm{~mL}$ & 1 & 2 & 3 \\
\hline 0.5 & 10 & $1 \mathrm{~h}-160^{\circ} \mathrm{C}$ & $1 \mathrm{~h}-180^{\circ} \mathrm{C}$ & $2 \mathrm{~h}-200^{\circ} \mathrm{C}$ \\
\hline
\end{tabular}

TABLE 3: Instrumental parameters for determination of metals by ICP-MS.

\begin{tabular}{ll}
\hline Forwarded power & $1200 \mathrm{~W}$ \\
Analog stage voltage & $-1800 \mathrm{~V}$ \\
Pulse stage voltage & $1100 \mathrm{~V}$ \\
Argon consumption & \\
$\quad$ Plasma generating flow & $15 \mathrm{~L} / \mathrm{min}$ \\
$\quad$ Auxiliary flow & $0.8 \mathrm{~L} / \mathrm{min}$ \\
$\quad$ Carrier flow & $1.4 \mathrm{~L} / \mathrm{min}$ \\
Sample consumption & $0.5 \mathrm{~mL} / \mathrm{min}$ \\
Peak resolution & $\sim 0.6 \mathrm{amu}$ \\
Detector operating modes & Pulse count and analog \\
Speed of peristaltic pump & $24 \mathrm{rpm}$ \\
Spray chamber & Cooling $\left(4^{\circ} \mathrm{C}\right)$ quartz \\
Mass range & $27-238 \mathrm{amu}$ \\
Sweeps/reading & 40 \\
Replicates & 3 \\
Dwell time & $50 \mathrm{~ms}$ \\
Scan mode & Peak hopping \\
Abundance sensitivity & $<5 \cdot 10^{-7}$ \\
$\quad$ Low mass & $<1 \cdot 10^{-7}$ \\
$\quad$ High mass &
\end{tabular}

liance with the standards matrix, and optimization of the instrument parameters.

Performance of the ICP-MS instrument strongly depends on the operating conditions. Tuning solution containing $\mathrm{Li}, \mathrm{Y}, \mathrm{Ce}, \mathrm{Tl}, \mathrm{Co}(10 \mu \mathrm{g} / \mathrm{L})$ in $2 \mathrm{wt} \%$ aqueous $\mathrm{HNO}_{3}$ was used to optimize the instrument (Agilent 7500c, USA) in terms of sensitivity, resolution, and mass calibration. ${ }^{140} \mathrm{Ce}^{16} \mathrm{O}^{+} /{ }^{140} \mathrm{Ce}^{+}$and ${ }^{137} \mathrm{Ba}^{2+} /{ }^{137} \mathrm{Ba}^{+}$ratios were used to minimize oxide ions and double-charged ions levels in the plasma that could interfere with the determination of some elements.

Measurement parameters such as carrier gas flow, torch position, speed of peristaltic pump, and dwell time were optimized with the aim of high sensitivity and low isobaric interferences. ICP-MS analysis was performed following the operating program and parameters shown in Table 3.
All ICP-MS data (final concentrations in analyzed solutions, calibrations, tunes, statistics, etc.) were obtained from ICP-MS Top Agilent program pack.

Final REE concentrations $(C, \mu \mathrm{g} / \mathrm{g})$ in oils were calculated using the following standard formula:

$$
C=\frac{\left(A_{\text {sample }}-\bar{A}_{\text {blanks }}\right) \cdot V}{m},
$$

where $A_{\text {sample }}$ is the concentration of each element in sample solution $(\mu \mathrm{g} / \mathrm{L}$ ) obtained from ICP-MS (counted by ICP-MS Top Agilent software), $A_{\text {blanks }}$ is the mean concentration of each element in blank solutions (nitric acid was pumped through the column in 3-5 repetitions), $V$ is the volume of oil (mobile phase) pumped through the column in CCC experiments, and $m$ is the mass of analyzed oil.

2.2.4. NAA. Measurements were conducted at Central Laboratory of Substance Analysis of Vernadsky Institute of Geochemistry and Analytical Chemistry RAS. Analyzed oil samples of 10-50 mg were placed in a bag of aluminum foil $10 \times 10 \mathrm{~mm}$ in size together with certified reference materials (ST-1A, effusive basalt; SGD-1A, intrusive basic rock; AN$\mathrm{G}$, intrusive basic rock). The bag is placed in an aluminum case and irradiated with a neutron flux of $1.2 \times 10^{13}$ neutron $\mathrm{cm}^{-2} \mathrm{~s}^{-1}$ for $15 \mathrm{~h}$. The samples are cooled for 6 days to reduce activity of radionuclides with $T_{1 / 2}<15 \mathrm{~h}$. Then gamma spectra of samples are measured using a $\mathrm{Ge}$ or a $\mathrm{Ge}(\mathrm{Li})$ detector with a multichannel pulse analyzer for activity levels of 100 and $2000 \mathrm{~s}$, respectively. Measurements are repeated after 6 to 10 days to distinguish gamma lines of relatively long-lived radionuclides. The gamma spectra obtained are processed using the program package described in $[8,9]$ and by comparing the normalized peak areas of the studied and reference samples. Element concentrations are calculated with regard to their concentrations in the reference samples.

2.3. Results and Discussion. Application of CCC for REE recovery was tested on Tengizskaya oil. Table 4 provides measured concentrations of 12 REE from Tengizskaya oil. Various volumes of analyzed oil $(52,104$, and $624 \mathrm{~mL})$ were pumped at the constant flow rate of $1.2 \mathrm{~mL} / \mathrm{min}$ through the CCC column rotating at $750 \mathrm{rpm}$. Minimal $\mathrm{HNO}_{3}$ concentration $(0.5 \mathrm{M})$ was used for all CCC experiments because of no emulsion at the oil-water interface [10]. Nitric acid with higher concentrations can form some emulsion on the oilwater interface and that means bleed of the stationary phase. It is obvious that concentration factor $(5,10$, and 60 , resp.) did not affect obtained REE concentrations. The choice of the concentration factor is upon sample quantity and sample preparation time. It is also clearly seen that concentrations 
TABLE 4: Measured REE concentration in Tengizskaya oil by ICP-MS after CCC preconcentration from different sample volumes of Tengizskaya oil.

\begin{tabular}{lccc}
\hline Element & & Concentration, $\mu \mathrm{g} / \mathrm{kg}$ \\
& $V_{M}=\mathbf{5 2 \mathrm { mL }}$ & $V_{M}=\mathbf{1 0 4 \mathrm { mL }}$ & $V_{M}=\mathbf{6 2 4 \mathrm { mL }}$ \\
\hline $\mathrm{Y}$ & $\mathbf{0 . 0 1 9} \pm 0.004$ & $\mathbf{0 . 0 2 1} \pm 0.004$ & $\mathbf{0 . 0 2 3} \pm 0.004$ \\
$\mathrm{La}$ & $\mathbf{0 . 1 3 3} \pm 0.02$ & $\mathbf{0 . 0 7 5} \pm 0.02$ & $\mathbf{0 . 0 9 1} \pm 0.02$ \\
$\mathrm{Ce}$ & $\mathbf{0 . 0 6} \pm 0.01$ & $\mathbf{0 . 0 6} \pm 0.01$ & $\mathbf{0 . 0 5} \pm 0.01$ \\
$\mathrm{Pr}$ & $\mathbf{0 . 0 0 6} \pm 0.001$ & $\mathbf{0 . 0 0 6} \pm 0.001$ & $\mathbf{0 . 0 0 7} \pm 0.001$ \\
$\mathrm{Nd}$ & $<0.001$ & $<0.001$ & $<0.001$ \\
$\mathrm{Sm}$ & $\mathbf{0 . 0 0 6} \pm 0.001$ & $\mathbf{0 . 0 0 4} \pm 0.001$ & $\mathbf{0 . 0 0 5} \pm 0.001$ \\
$\mathrm{Eu}$ & $\mathbf{0 . 0 1 8} \pm 0.004$ & $\mathbf{0 . 0 2 1} \pm 0.004$ & $\mathbf{0 . 0 1 7} \pm 0.004$ \\
$\mathrm{Gd}$ & $\mathbf{0 . 0 1 1} \pm 0.003$ & $\mathbf{0 . 0 1 4} \pm 0.003$ & $\mathbf{0 . 0 1 3} \pm 0.003$ \\
$\mathrm{~Tb}$ & $\mathbf{0 . 0 0 2 0} \pm 4 E-4$ & $\mathbf{0 . 0 0 2 0} \pm 4 E-4$ & $\mathbf{0 . 0 0 2 0} \pm 4 E-4$ \\
$\mathrm{Dy}$ & $\mathbf{0 . 0 0 3 0} \pm 6 E-4$ & $\mathbf{0 . 0 0 3 0} \pm 6 E-4$ & $\mathbf{0 . 0 0 3 0} \pm 4 E-4$ \\
$\mathrm{Ho}$ & $\mathbf{0 . 0 0 1 0} \pm 2 E-4$ & $\mathbf{0 . 0 0 1 0} \pm 2 E-4$ & $\mathbf{0 . 0 0 1 0} \pm 4 E-4$ \\
$\mathrm{Er}$ & $\mathbf{0 . 0 0 2 0} \pm 4 E-4$ & $\mathbf{0 . 0 0 2 0} \pm 4 E-4$ & $\mathbf{0 . 0 0 3 0} \pm 4 E-4$ \\
$\mathrm{Yb}$ & $\mathbf{0 . 0 0 5} \pm 0.001$ & $\mathbf{0 . 0 0 5} \pm 0.001$ & $\mathbf{0 . 0 0 5} \pm 0.001$ \\
$\mathrm{Lu}$ & $<0.0005$ & $<0.0005$ & $<0.0005$ \\
\hline
\end{tabular}

TABle 5: Measured REE concentration in Tengizskaya, West Siberian, and composite oils by ICP-MS after CCC preconcentration.

\begin{tabular}{lccc}
\hline Element & & Concentration in oils, $\mu \mathrm{g} / \mathrm{kg}$ & \multicolumn{1}{c}{ Composite } \\
& Tengizskaya & West Siberian & $\mathbf{0 . 0 1 2} \pm 0.002$ \\
$\mathrm{Y}$ & $\mathbf{0 . 0 1 9} \pm 0.004$ & $\mathbf{0 . 0 0 7} \pm 0.001$ & $\mathbf{0 . 0 3 7} \pm 0.004$ \\
$\mathrm{La}$ & $\mathbf{0 . 1 3 3} \pm 0.023$ & $\mathbf{0 . 2 0 8} \pm 0.036$ & $\mathbf{0 . 0 0 4 0} \pm 8 E-4$ \\
$\mathrm{Ce}$ & $\mathbf{0 . 0 6} \pm 0.01$ & $\mathbf{0 . 0 1 2} \pm 0.002$ & $\mathbf{0 . 0 0 2 0} \pm 4 E-4$ \\
$\mathrm{Pr}$ & $\mathbf{0 . 0 0 6} \pm 0.001$ & $\mathbf{0 . 0 0 2 0} \pm 4 E-4$ & $\mathbf{0 . 0 0 3 0} \pm 6 E-4$ \\
$\mathrm{Nd}$ & $<0.001$ & $\mathbf{0 . 0 0 7} \pm 0.002$ & $\mathbf{0 . 0 0 2 0} \pm 4 E-4$ \\
$\mathrm{Sm}$ & $\mathbf{0 . 0 0 6} \pm 0.001$ & $\mathbf{0 . 0 0 2 0} \pm 4 E-4$ & $\mathbf{0 . 0 0 0 4} \pm 1 E-4$ \\
$\mathrm{Eu}$ & $\mathbf{0 . 0 1 8} \pm 0.004$ & $\mathbf{0 . 0 0 2 0} \pm 4 E-4$ & $\mathbf{0 . 0 0 0 4} \pm 1 E-4$ \\
$\mathrm{Gd}$ & $\mathbf{0 . 0 1 1} \pm 0.003$ & $<0.0002$ & $\mathbf{0 . 0 0 0 2} \pm 5 E-5$ \\
$\mathrm{~Tb}$ & $\mathbf{0 . 0 0 2 0} \pm 4 E-4$ & $\mathbf{0 . 0 0 3 0} \pm 6 E-4$ & $\mathbf{0 . 0 0 0 5} \pm 1 E-4$ \\
$\mathrm{Dy}$ & $\mathbf{0 . 0 0 3 0} \pm 6 E-4$ & $\mathbf{0 . 0 0 1 0} \pm 2 E-4$ & $\mathbf{0 . 0 0 0 3} \pm 1 E-5$ \\
$\mathrm{Ho}$ & $\mathbf{0 . 0 0 1 0} \pm 2 E-4$ & $\mathbf{0 . 0 0 1 0} \pm 2 E-4$ & $\mathbf{0 . 0 0 0 2} \pm 1 E-5$ \\
$\mathrm{Er}$ & $\mathbf{0 . 0 0 2 0} \pm 4 E-4$ & $\mathbf{0 . 0 0 1 0} \pm 2 E-4$ & $\mathbf{0 . 0 0 0 5} \pm 1 E-4$ \\
$\mathrm{Yb}$ & $\mathbf{0 . 0 0 5} \pm 0.001$ & $\mathbf{0 . 0 0 1 0} \pm 2 E-4$ & $<0.0005$ \\
$\mathrm{Lu}$ & $<0.0005$ & $<0.0005$ & \\
\hline
\end{tabular}

of REE are very low with $\Sigma \mathrm{Ln}_{\mathrm{N}} \sim 0.2 \mathrm{mg} / \mathrm{t}$. In case of low concentration of REE in oil, the highest concentration factor (60 or even higher) should be used especially with the other instrumentation techniques (ICP-AES, AAS).

It should be noted that concentrations of REE in oils are at very low level that cause difficulties of their direct detection.

There are comparative data of REE determination in 3 different oils: Tengizskaya, West Siberian, and composite in Table 5. REE distributions and ratios are given in Figure 2 and Table 6, respectivelly. For both oils, $\Sigma \operatorname{Ln}_{\mathrm{N}}$ was about $0.2 \mathrm{mg} / \mathrm{t}$, while composite oil was diluted by lighter kerosene fraction $\left(\sum \mathrm{Ln}_{\mathrm{N}} \sim 0.1 \mathrm{mg} / \mathrm{t}\right)$. It is also clear that REE ratios are differentiated.
REE contents and rations of oils from 3 source regions are different (Figure 2, Table 6). Such REE ratios are usually used as geochemical certificates for oils. In the meantime, we obtained "less DL" results for REE in all oils after autoclaves decomposition. DLs were in the range of $0.3-0.04 \mu \mathrm{g} / \mathrm{kg}$ and it was impossible to compare results of the two sample preparation techniques.

Therefore, NAA was used in this work as an instrumentation method that enables direct oil analysis (REE detection in the native forms). Only comparison with NAA could be applied as correctness criteria for combined CCCICP-MS method. Comparative REE ratios obtained via NNA and CCC-ICP-MS are presented in Table 7. These results prove correctness of both the methods of REE ratios 


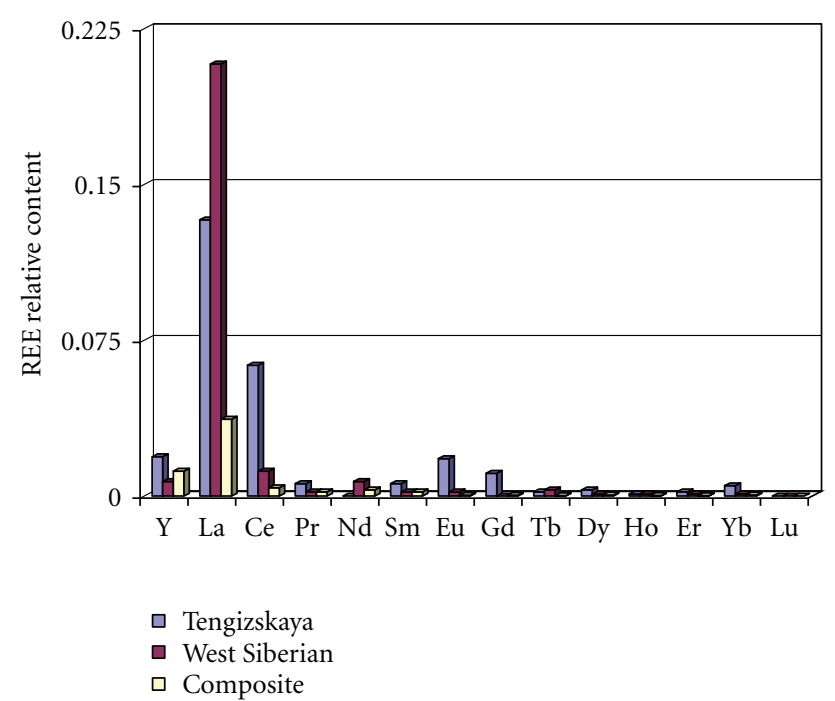

FIgUre 2: Relative REE distributions in Tengizskaya, West Siberian, and composite oil samples.

TABLE 6: Comparative REE ratios of Tengizskaya, West Siberian, and composite oils obtained by ICP-MS after CCC preconcentration.

\begin{tabular}{lcccc}
\hline \multirow{2}{*}{ Oil } & \multicolumn{4}{c}{ Elements ratios } \\
& $\mathrm{La} / \mathrm{Ce}$ & $\mathrm{Nd} / \mathrm{Sm}$ & $\mathrm{Eu} / \mathrm{Gd}$ & $\mathrm{Dy} / \mathrm{Ho}$ \\
\hline Tengizskaya & $\mathbf{2 . 1}$ & - & $\mathbf{1 . 8}$ & 3.0 \\
West Siberian & $\mathbf{1 7}$ & $\mathbf{3 . 5}$ & - & $\mathbf{1 . 0}$ \\
composite & $\mathbf{9 . 3}$ & $\mathbf{1 . 5}$ & $\mathbf{1 . 0}$ & $\mathbf{1 . 7}$ \\
\hline
\end{tabular}

TABle 7: Comparative REE ratios of Tengizskaya oil obtained by ICP-MS after CCC preconcentration and by NAA.

\begin{tabular}{lcccc}
\hline \multirow{2}{*}{ Method } & \multicolumn{4}{c}{ Elements ratios } \\
& $\mathrm{La} / \mathrm{Ce}$ & $\mathrm{Nd} / \mathrm{Sm}$ & $\mathrm{Eu} / \mathrm{Gd}$ & $\mathrm{Dy} / \mathrm{Ho}$ \\
\hline NAA & $\mathbf{1 . 8}$ & $\mathbf{4 . 2}$ & $\mathbf{1 . 6}$ & $\mathbf{3 . 0}$ \\
ICP-MS & $\mathbf{2 . 1}$ & - & $\mathbf{1 . 8}$ & $\mathbf{3 . 0}$ \\
\hline
\end{tabular}

determination. Both results are not distorted, that is, very important for studying base geochemical processes of the oil genesis.

\section{Conclusions}

It has been shown that REE contents and rations of oils from 3 source regions are different. Concentrations of REE are very low with $\Sigma \mathrm{Ln}_{\mathrm{N}} \sim 0.2 \mathrm{mg} / \mathrm{t}$ in 3 oil samples studied. Composite oil has $\Sigma \mathrm{Ln}_{\mathrm{N}} \sim 0.1 \mathrm{mg} / \mathrm{t}$ as diluted one with light fraction. Such ratios are usually used as geochemical certificates for oils. Comparative REE ratios obtained via NNA and suggested combined CCC-ICP-MS method are in close agreement. Correct REE ratios could be used for geochemical studies dedicated to oil genesis research.

\section{Acknowledgment}

The authors are grateful to Russian Foundation for Basic Research (RFBR) Project no. 09-03-00757.

\section{References}

[1] A. F. Oluwole, O. I. Asubiojo, J. I. Nwachukwu et al., "Neutron activation analysis of nigerian crude oils," Journal of Radioanalytical and Nuclear Chemistry, vol. 168, no. 1, pp. 145-152, 1993.

[2] S. M. Eggins, J. D. Woodhead, L. P. J. Kinsley et al., "A simple method for the precise determination of $\geq 40$ trace elements in geological samples by icpms using enriched isotope internal standardisation," Chemical Geology, vol. 134, no. 4, pp. 311326, 1997.

[3] A. Akinlua, N. Torto, and T. R. Ajayi, "Determination of rare earth elements in niger delta crude oils by inductively coupled plasma-mass spectrometry," Fuel, vol. 87, no. 8-9, pp. 14691477, 2008.

[4] T. A. Maryutina, A. V. Soin, and O. N. Katasonova, "Countercurrent chromatography for oil analysis: retention features and kinetic effects," Journal of Chromatography, vol. 1216, no. 19, pp. 4232-4236, 2009.

[5] A. V. Soin, T. A. Maryutina, and N. S. Musina, "Behavior of oil-aqueous solution systems in rotating coil column," Journal of Chromatography and Separation Techniques, vol. 2, no. 1, pp. 106-110, 2011.

[6] R. P. Gottikh, S. F. Vinokurov, and B. I. Pisotskii, "Rare-earth elements as geochemical criteria of endogenous sources of microelements contained in oil," Doklady Earth Sciences, vol. 425, no. 2, pp. 325-329, 2009.

[7] W. D. Conway, Countercurrent Chromatography. Apparatus, Theory and Applications, VCH, New York, NY, USA, 1990.

[8] G. M. Kolesov, N. A. Shubina, and A. Y. Lyul, "Optimizing instrumental neutron activation analysis of extraterrestrial materials: fragments of lunar rocks, meteorites, chondrules, and ultrarefractory inclusions," Journal of Analytical Chemistry, vol. 56, no. 11, pp. 1022-1028, 2001.

[9] N. A. Shubina and G. M. Kolesov, "Advantage factors in optimized instrumental neutron activation analysis of some biosphere samples," Journal of Analytical Chemistry, vol. 55, no. 3, pp. 231-238, 2000.

[10] T. A. Maryutina and A. V. Soin, "Novel approach to the elemental analysis of crude and diesel oil," Analytical Chemistry, vol. 81, no. 14 , pp. 5896-5901, 2009. 


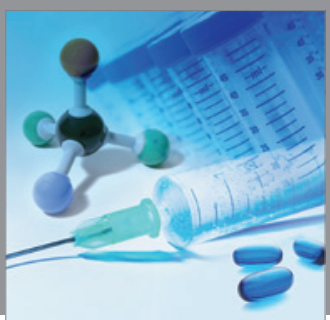

International Journal of

Medicinal Chemistry

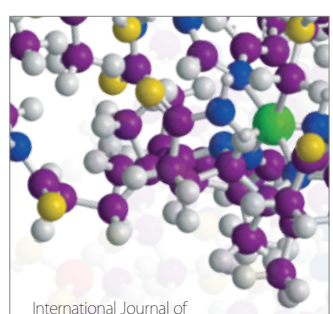

Carbohydrate Chemistry

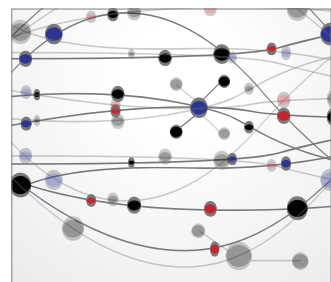

The Scientific World Journal
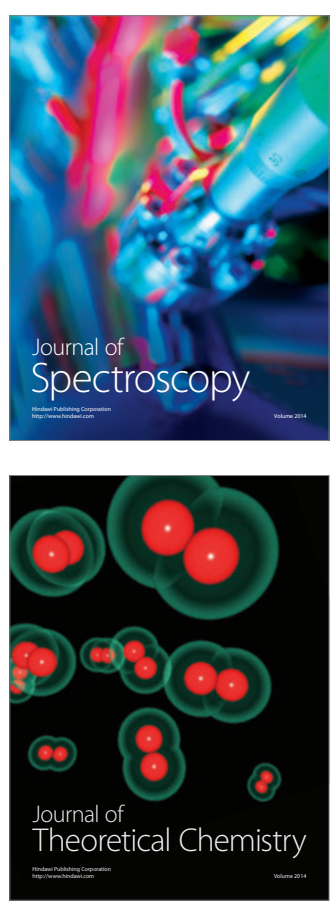
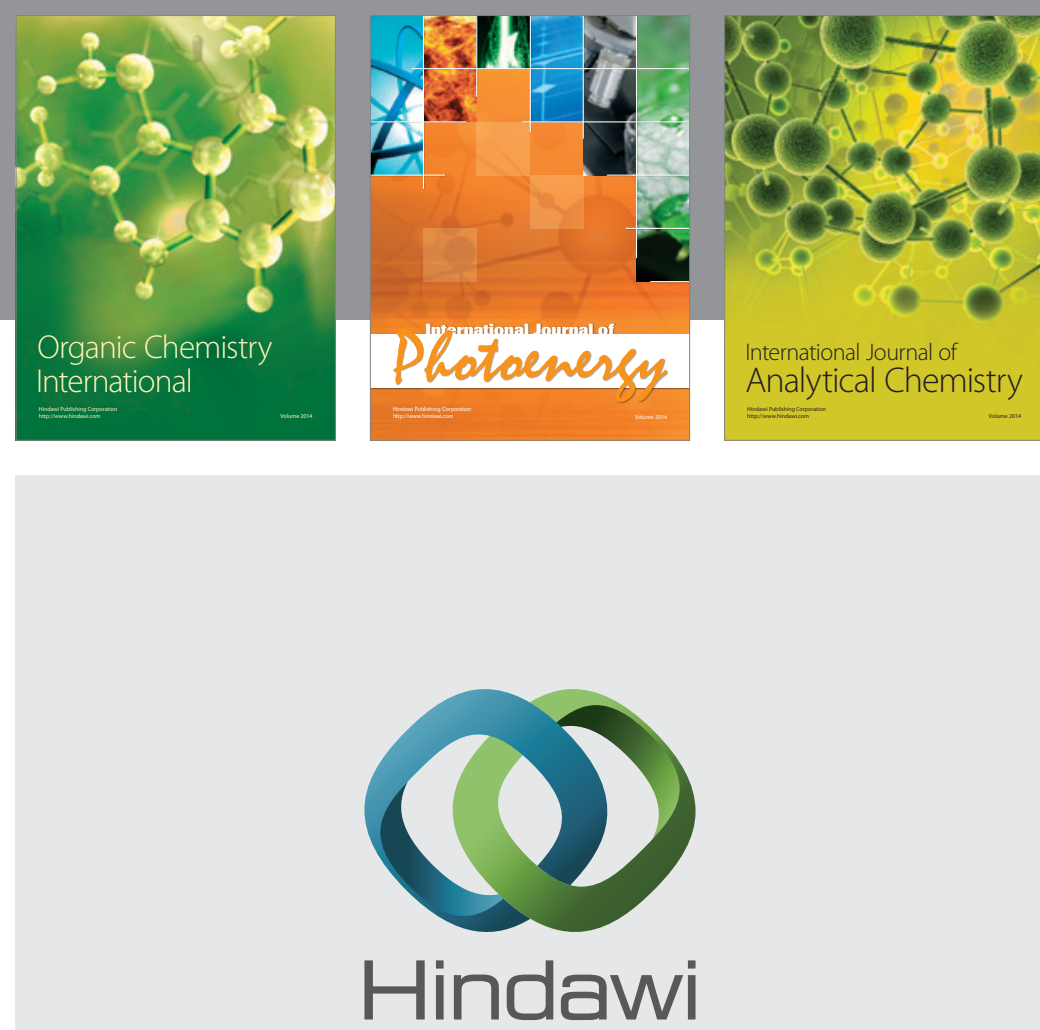

Submit your manuscripts at

http://www.hindawi.com
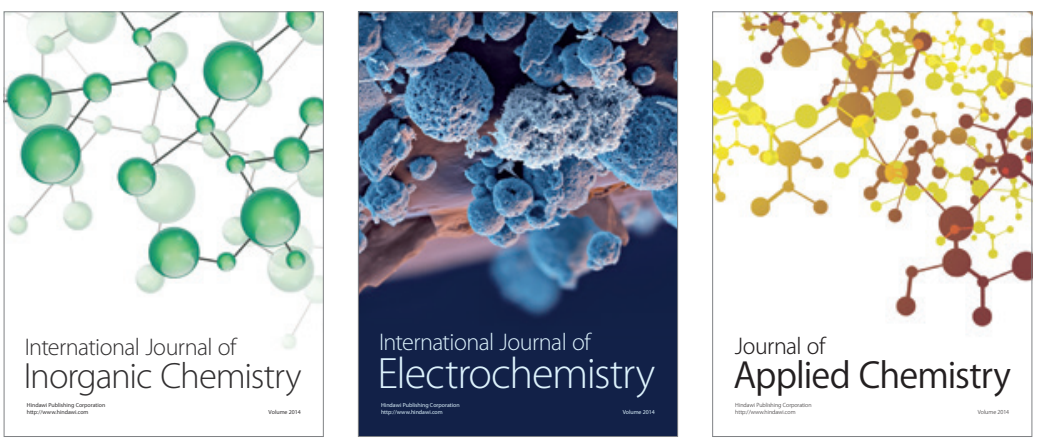

Journal of

Applied Chemistry
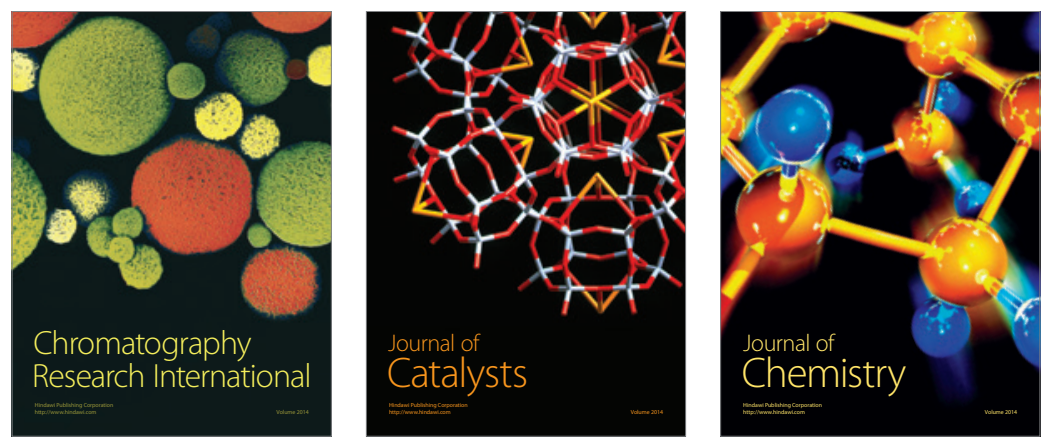
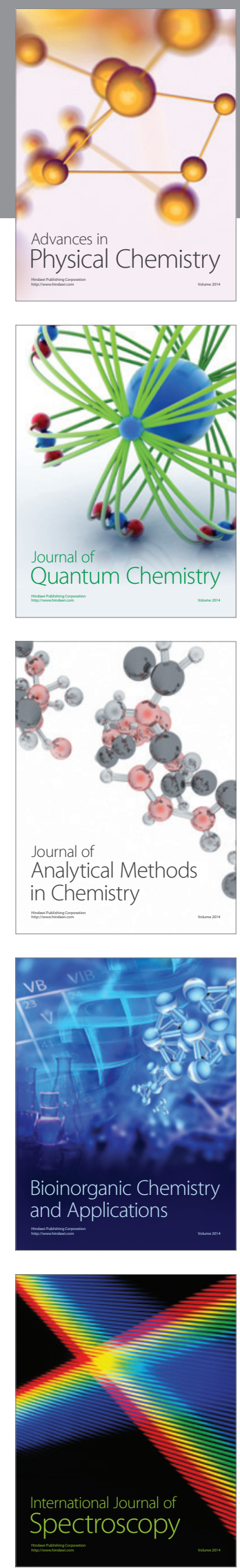